\title{
HIÊU QUẢ SỬ DỤNG SỮA BỔ SUNG ĐA VI CHẤT CARE100GOLD ĐốI VớI TİNH TRẠG THIẾU VI CHẤT DINH DƯỡNG Ở TRẺ EM 36-60 THÁNG
}

\section{TÓM TẮT}

Mục tiêu: Đánh giá hiệu quả của việc sử dụng sữa cảo năng lượng, bổ sung đa vi chất Care100Gold đối với tình trạng thiếu vi chất dinh dưỡng ở trẻ em 36-60 tháng tuổi tại huyện Tiền Hải, tỉnh Thái Bình. Phương pháp nghiên cứu: nghiên cứu thử nghiệm can thiệp có nhóm chứng trên 179 trẻ em 36-60 tháng không bị thừa cân béo phì. Trẻ mối ngày được uống $360 \mathrm{ml}$ sữa, chia làm 2 lần, nhóm can thiệp sử dụng sữa bột Care100Gold cao năng lượng bổ sung đa vi chất, nhóm chứng sử dụng sữa nước thông thường, không bổ sung vi chất. Kết quả: sau 4 tháng can thiệp, mức gia tăng nồng độ sắt huyết thanh và hemoglobin huyết thanh ở nhóm sử dụng sữa Care100Gold cao hơn có ý nghĩa thống kê so với nhóm chứng $(3,85 \mathrm{mcmol} / \mathrm{L}$ so với $0,1 \mathrm{mcmol} / \mathrm{L}$ và $8,0 \mathrm{~g} / \mathrm{L}$ so với $4,0 \mathrm{~g} / \mathrm{L} ; \mathrm{p}<0,05)$. Nồng độ ferritine huyết thanh, kẽm huyết thanh và IgA của nhóm sử dụng sữa Care100Gold có xu hướng tăng cao hơn, tuy sự khác biệt chưa có ý nghĩa thống kê so với nhóm chứng. Kết luận: Sử dụng sản phẩm sữa Care100Gold cao năng lưởng, bổ sung đa vi chất dinh dưỡng có hiêu quả cải thiện rõ rệt tình trạng thiếu máu thiếu sắt và thiếu kẽm, cũng như xu hướng gia tăng chỉ số miễn dịch, ở trẻ em 36-60 tháng tuổi sau 4 tháng can thiệp.

Tư khoá: trẻ em, đa vi chất dinh dương, sũa bổ sung đa vi chất.

\section{SUMMARY}

THE EFFICIENCY OF USING MULTIMICRONTRIENTS FORTIFIED MILK CARE100GOLD ON MICRONUTRIENTS DEFICIENCY AMONG CHILDREN 36-60 MONTHS

Objective: To evaluate the effectiveness of using high calories, multi-micronutrients fortified milk Care100Gold on micronutrient deficiency in children 36-60 months old in Tien Hai district, Thai Binh province. Methods: a controlled intervention trial study was carried out on 179 children $36-60$ months old who are not overweight and obese. Children were given $180 \mathrm{ml}$ of milk, 2 times a day. The intervention group used high calories powder milk fortified with multi-micronutrients named Care100Gold, the control group used milk without multi-micronutrients. Results: after 4 months of intervention, the increase in serum iron and serum hemoglobin concentration in the intervention group was statistically significantly higher than that of the control group $(3.85 \mathrm{mcmol} / \mathrm{L}$ compared to $0.1 \mathrm{mcmol} / \mathrm{L}$ and $8.0 \mathrm{~g} / \mathrm{L}$ compared with

*Viện Y học Úng dung Việt Nam

Chịu trách nhiệm chính: Trương Hồng Sơn

Email: vienyhocungdung@gmail.com

Ngày nhận bài: 20.9.2021

Ngày phản biên khoa hoc: 19.11.2021

Ngày duyệt bài: 26.11.2021
$4.1 \mathrm{~g} / \mathrm{L} ; \mathrm{p}<0.05)$. Serum ferritin, serum zinc and IgA of intervention group tended to higher than that of the control group but not statistically significant. Conclusions: Using high calories milk fortified with multi-micronutrients Care100Gold effectively improved iron deficiency anemia and zinc deficiency as well as tended to increase immune indicators in children 3660 months after 4 months of intervention. milk.

Keywords: children, multi-micronutrients fortified

\section{I. ĐĂTT VẤN ĐỀ}

Thiếu vi chất dinh dưỡng ở trẻ em dưới 5 tuổi, đặc biệt là thiếu máu do thiếu sắt, thiếu kẽm còn phổ biến ở Việt Nam ở tỷ lệ cao đang chú ý. Thiếu vi chất là yếu tố nguy cơ kết hợp với SDD thấp còi, nhẹ cân ở trẻ em trong 1000 ngày đầu đời.

Nhiều nghiên cứu đã được tiến hành trên thế giới và Việt Nam về vai trò của bổ sung chất dinh dưỡng trển trẻ nhỏ và có nhiều kết quả khác nhau. Tại Việt Nam, nhằm cải thiện tình trạng dinh dưỡng của trẻ em mẫu giáo và học sinh tiểu học, chương trình "sữa học đường" đã ra đời giúp trẻ được uống sữa hàng ngày, nhằm giảm tỷ lệ suy dinh dưỡng, nâng cao tầm vóc, thể lực của trẻ em, góp phần phát triển nguồn nhân lực trong tương lai. Tuy nhiên, hầu hết các chương trình can thiệp đều sử dụng giải pháp tăng cường đa vi chất hoặc bổ sung năng lượng dưới dạng sữa hộp năng lượng thấp. Số lượng nghiên cứu áp dụng giải pháp bổ sung sữa với đậm độ năng lượng cao còn hạn chế. Với trẻ nhỏ, việc tìm ra dạng thực phẩm cung cấp tốt về mặt nhu cầu năng lượng vẫn còn khó khăn bởi trẻ khó chấp nhận, khó hợp khẩu vị trẻ, giá thành cao. Do vậy, việc lựa chọn bổ sung dạng thực phẩm mong muốn đáp ứng nhu cầu cả năng lượng và vi chất dinh dưỡng cho trẻ có nguy có suy dinh dưỡng nói chung đặc biệt là suy dinh dưỡng thấp còi đã và đang gặp nhiều khó khăn.

Nhằm cung cấp thêm những bằng chứng khoa học về vai trò của sản phẩm có đậm độ năng lượng cao và giàu các vi chất dinh dưỡng trong cải thiện tình trạng vi chất và miễn dịch của trẻ nhỏ, nghiên cứu đã được tiến hành với mục tiêu: Đánh giá hiệu quả sử dụng sữa Care100Gold cao năng lượng và giàu vi chất đến một số chì tiêu vi chất dinh dưỡng, miễn dịch của trẻ lứa tuổi 36-60 tháng tuổi, không bi thừa cân béo phi. 
II. ĐỐI TƯợNG VÀ PHƯƠNG PHÁP NGHIÊN CỨU

Thiết kế nghiên cứu: Thử nghiệm can thiệp có nhóm chứng

Đối tượng, địa điểm nghiên cứu: trẻ em trong độ tuổi 36-60 tháng, thuộc 2 trường mầm non Tây Lương và Tây Tiến, huyện Tiền Hải-Thái Bình. Trẻ không béo phì ( $\mathrm{WHZ}<2 \mathrm{SD})$ theo chuẩn WHO, không bị bệnh cấp tính (ho sốt, tiêu chảy), không dị tật bẩm sinh, bố mẹ đồng ý tham gia, đã được chọn và phân bổ ngẫu nhiên vào 2 nhóm nghiên cứu, tương ứng với sử dụng 2 loại sữa khác nhau.

Cỡ mẫu được tính nhằm so sánh sự khác biêt giữa 2 giá trị trung bình trước và sau can thiềp giữa hai nhóm, dự kiến $15 \%$ bỏ cuộc; số mẫu chọn là 180 trẻ cho hai nhóm.

Sản phẩm can thiệp: Nhóm Can thiệp sử dụng sữa bột giàu năng lượng CARE100GOLD, do công ty trách nhiệm hữu hạn dinh dưỡng Nutricare sản xuất có giá trị dinh dưỡng $120 \mathrm{kcal} / 100 \mathrm{ml}$, bổ sung thêm đa vi chất $(A, D$, $\mathrm{E}, \mathrm{K}$, nhóm $\mathrm{B}, \mathrm{Ca}, \mathrm{P}, \mathrm{Mg}, \mathrm{Fe}, \mathrm{Zn}, \mathrm{K}, \mathrm{Mn}, \mathrm{Cu}, \mathrm{I}$, selen). Nhóm chứng sử dụng sản phẩm sữa nước thông thường có năng lượng 65,7 $\mathrm{kcal} / 100 \mathrm{ml}$ và không bổ sung đa vi chất.

Quy trình, thời gian can thiệp: Trẻ được uống sữa 2 lần/ngày vào $9 \mathrm{~h}$ sáng và $3 \mathrm{~h}$ chiều, mỗi lần $180 \mathrm{ml} \times 5$ ngày/tuần, trong 4 tháng liên tục. Trẻ được uống sữa tại một phòng riêng tách biệt với lớp học chung. Tại buổi uống sữa, cô giáo ghi lại tình trạng uống sữa (số lượng), bệnh tật và các vấn đề bất thường của trẻ vào sổ theo dõi và báo cáo cho nghiên cứu viên.

Nhân trắc: mỗi tháng trẻ được cân đo nhân trắc một lần, cân nặng, chiều cao, tình trạng dinh dưỡng

Xét nghiệm hóa sinh, miễn dịch: Khi bắt đầu và kết thúc 4 tháng can thiệp, các đối tượng được lấy $4 \mathrm{ml}$ máu tĩnh mach lúc đói, máu được lấy từ 7-9h sáng, bảo quản lạnh, tránh ánh sáng, ly tâm tách huyết thanh sau $3 \mathrm{~h}$. Các mẫu huyết thanh được giữ ở nhiệt độ $-20^{\circ} \mathrm{C}$ cho đến khi mẫu được phẩn tích. Kẽm huyết thanh được xác định bằng phương pháp AAS, khi nồng độ kẽm $<65 \mu \mathrm{g} / \mathrm{dL}$ được coi là thiếu kẽm [1]. Hemoglobin máu được định lượng trên máy Sysmex-XP100. Sắt, Ferritin, IgA huyết thanh được định lượng trên máy Biosystem A25 (Span). $\mathrm{Hb}<110 \mathrm{~g} / \mathrm{L}$ được coi là thiếu máu; khi cả $\mathrm{Hb}<110$ và Ferritin $<12 \mu \mathrm{g} / \mathrm{L}$ là thiếu máu do thiếu sắt [2].

Thống kê: sử dụng các phần mềm Epidata 3.1, Stata 12. Các số liệu được trình bày và sử dụng test thống kê thích hợp, $\mathrm{p}<0,05$ được coi là khác biệt có ý nghĩa.

Đạo đức nghiên cứu: Đề tài được Hội đồng Khoa học và Hội đồng đạo đức - Viện Y học ứng dụng Việt Nam thông qua.

\section{KẾT QUẢ NGHIÊN CỨU}

\section{1 Đặc điểm của đối tượng nghiên} cứu.Tổng số có 180 trẻ tham gia nghiên cứu. Trong quá trình tham gia nghiên cứu, có 1 trẻ bố me xin rút khỏi nghiên cứu vì lý do gia đình. Còn lại 179 trẻ tham gia nghiên cứu.

Bảng 1. Đặc điểm của đôî tượng nghiên cứu trước can thiệp

\begin{tabular}{|c|c|c|c|c|}
\hline Chỉ số & & $\begin{array}{c}\text { Nhóm chứng } \\
(n=90)\end{array}$ & $\begin{array}{c}\text { Nhóm can thiệp } \\
(n=89)\end{array}$ & p-value \\
\hline Tháng tuối & Median $(95 \% \mathrm{CI})$ & $49,3(33,9 ; 55,2)$ & $50,3(34,6 ; 54,9)$ & $p^{1}>0,05$ \\
\hline \multirow{2}{*}{ Giới tính n (\%) } & Nam & $39(43,3)$ & $40(44,9)$ & \multirow{2}{*}{$p^{2}>0,05$} \\
\hline & Nữ & $51(56,7)$ & $49(55,1)$ & \\
\hline Chiều cao $(\mathrm{cm})$ & Median $(95 \% \mathrm{CI})$ & $97(88,4 ; 108,8)$ & $99.7(89,2 ; 111)$ & $p^{1}>0,05$ \\
\hline Cân I & Median ( & $13,4($ & 13,9 & \\
\hline Hemoglobin $(\mathrm{g} / \mathrm{L})$ & Median $(95 \% \mathrm{CI})$ & $120(105 ; 136)$ & $120(106 ; 135)$ & $p^{1}>0,05$ \\
\hline Tý lê thiếu máu n (\%) & $\mathrm{N}(\%)$ & & $11(12,4)$ & $p^{2}>0,05$ \\
\hline Sắt huyết & Median $(95 \% \mathrm{CI})$ & $17,4(7,6 ; 25,3)$ & $15,2(7,2 ; 23,6)$ & 0,05 \\
\hline Ferritin huyêtt thanh & Median $(95 \% \mathrm{CI})$ & $54,9(18,6 ; 85,5)$ & $57,1(13,8 ; 86,9)$ & $p^{1}>0,05$ \\
\hline Kẽm huyết th & & & & \\
\hline IgA huyết thanh(mg/dL) & Median $(95 \% \mathrm{CI})$ & $87,2(45,7 ; 146,3)$ & $88,2(45,2 ; 153)$ & $\mathrm{p}^{1}>0,05$ \\
\hline
\end{tabular}

$\mathrm{p}^{1}$ : Mann-Whitney test; $\mathrm{p}^{2}: \mathrm{x}^{2}$ test.

Bảng 3.2 cho thấy trước can thiệp không có sự khác biệt biệt ý nghĩa giữa 2 nhóm nghiên cứu về tất cả các chỉ số tuổi trung bình, giới tính , Hb máu, thiếu máu, sắt, kẽm, ferritin, IgA huyết thanh.

Bảng 2. Hiệu quả can thiệp đến một số chỉ số vi chât, miến dịch của trẻ

\begin{tabular}{|c|c|c|c|c|}
\hline Chỉ số & Thời điếm & Nhóm chứng (n=90) & Nhóm can thiệp (n=89) & p-value \\
\hline Nồng độ sắt & T0 & $17,4(7,6 ; 25,3)$ & $15,2(7,2 ; 23,6)$ & $\mathrm{p}^{1}>0,05$ \\
\hline
\end{tabular}




\begin{tabular}{|c|c|c|c|c|}
\hline \multirow{2}{*}{$\begin{array}{l}\text { huyết thanh } \\
(\mu \mathrm{mol} / \mathrm{L})\end{array}$} & T4 & $17,0(8,2 ; 30,9)$ & $18,3(11,6 ; 28,4)$ & $\mathrm{p}^{1}>0,05$ \\
\hline & T4-T0 & $0,1(-9,8 ; 15,6)$ & $3,85(-35 ; 39,3)$ & $\mathrm{p}^{1}<0,05$ \\
\hline \multirow{3}{*}{$\begin{array}{l}\text { Nồng đố } \\
\text { Hemoglobin } \\
(\mathrm{g} / \mathrm{L})\end{array}$} & T0 & $120(105 ; 136)$ & $120(106 ; 135)$ & $p^{2}>0,05$ \\
\hline & $\mathrm{T} 4$ & $125(106,5 ; 139)$ & $127(112 ; 145)$ & $\mathrm{p}^{1}<0,05$ \\
\hline & T4-T0 & $4(-10,5 ; 23)$ & $8(-1 ; 19)$ & $\mathrm{p}^{1}<0,05$ \\
\hline \multirow{3}{*}{$\begin{array}{c}\text { Nông độ } \\
\text { Ferritine huyết } \\
\text { thanh }(\mu \mathrm{g} / \mathrm{L})\end{array}$} & T0 & $54,9(18,6 ; 85,5)$ & $57,1(13,8 ; 86,9)$ & $p^{1}>0,05$ \\
\hline & T4 & $57,7(25,9 ; 78,9)$ & $61(36,6 ; 82,4)$ & $p^{1}<0,05$ \\
\hline & T4-T0 & $3,9(-35 ; 39,3)$ & $5,3(-17,4 ; 32,8)$ & $p^{1}>0,05$ \\
\hline \multirow{3}{*}{$\begin{array}{l}\text { Nồng độ kẽm } \\
\text { huyết thanh } \\
(\mu \mathrm{g} / \mathrm{dL})\end{array}$} & T0 & $70,4(45 ; 95,6)$ & $66,0(49,9 ; 81,5)$ & $\mathrm{p}^{1}<0,05$ \\
\hline & T4 & $72,5(55,5 ; 96,5)$ & $73(57 ; 93)$ & $p^{1}>0,05$ \\
\hline & T4-T0 & $5,2(-22,8 ; 33,4)$ & $6,2(-9,8 ; 29,31)$ & $p^{1}>0,05$ \\
\hline \multirow{3}{*}{$\begin{array}{l}\text { Nồng độ IgA } \\
\text { (mg/dL) }\end{array}$} & T0 & $87,2(45,7 ; 146,3)$ & $88,2(45,2 ; 153)$ & $p^{1}>0,05$ \\
\hline & $\mathrm{T} 4$ & $105,9(67,3 ; 147,8)$ & $110,8(56,1 ; 175,8)$ & $p^{1}>0,05$ \\
\hline & T4-T0 & $16,3(-23,8 ; 63,1)$ & $19,3(-11,8 ; 66,4)$ & $p^{1}>0,05$ \\
\hline
\end{tabular}

Số liệu được triình bày dưới dạng Median (95\%CI); p1: Mann-Whitney test;;

Bảng 3.2 cho thấy sau 4 tháng can thiệp, nồng độ $\mathrm{Hb}$ và Ferritin huyết thanh của trẻ ở sử dụng sữa Care100Gold cao hơn có ý nghĩa thống kê so với nhóm chứng $(p<0,05)$. Các chỉ số kẽm và IgA huyết thanh chữa thấy có sự khác biệt về gia tăng sau 4 tháng can thiệp giữa 2 nhóm.

Bảng 3. Thay đổi tỷ lệ thiếu vì chất dinh dướng sau 4 tháng can thiệp

\begin{tabular}{|c|c|c|c|}
\hline Chỉ số & Gíai đoạn & Nhóm chứng $(n=90)$ & Nhóm can thiệp $(n=89)$ \\
\hline \multirow{2}{*}{$\begin{array}{c}\text { Tỷ lệ trẻ thiếu } \\
\text { máu, } \mathrm{n}(\%)\end{array}$} & T0 & $9(10,0)$ & $11(12,4)$ \\
\hline & T4 & $5(6,3)$ & $4(4,8)$ \\
\hline \multirow{2}{*}{$\begin{array}{l}\text { Tỷ lệ trẻ thiếu } \\
\text { kẽm, n (\%) }\end{array}$} & T0 & $32(35,56)$ & $35(39,33)$ \\
\hline & T4 & $19(23,75)$ & $13(15,66)$ \\
\hline
\end{tabular}

Số liệu được trình bày dưới dạng $\mathrm{n}(\%) ; \mathrm{p}: \mathrm{x}^{2}$ test.

Bảng 3.3 trên cho thấy, tỷ lệ trẻ thiếu máu và tỷ lệ trẻ thiếu kẽm ở cả nhóm chứng và nhóm sử dụng sữa Care100Gold đều có sự cải thiện sau 4 tháng can thiệp. Sau 4 tháng can thiệp, tỷ lệ trẻ thiếu máu ở nhóm sử dụng sữa Care100Gold giảm từ $12,4 \%$ xuống còn $4,8 \%$; tỷ lệ thiếu kẽm giảm từ $39,33 \%$ xuống còn $15,66 \%$. Trong khi đó, mức giảm 2 tỷ lệ này ở nhóm chứng thấp hơn ( $10 \%$ xuống còn $6,3 \%$ và $35,56 \%$ xuống còn $23,75 \%$ )

\section{BÀN LUÂNN}

Nghiên cứu của chúng tôi đã sử dụng các chỉ số: $\mathrm{Hb}$, sắt huyết thanh và ferritin huyết thanh đánh giá tình trạng thiếu máu, kẽm huyết thanh đánh giá tình trạng kẽm, IgA cho thấy tình trạng miễn dịch ở trè. Những chỉ số được chọn để đánh giá là những chỉ số điển hình, sự thiểu hụt các chỉ số này hiện vẫn đang là vấn đề sức khoẻ cộng đồng của nhóm trẻ 3-5 tuổi ở Viêt Nam. Những chỉ số này có liên quan chặt chể tới sự phát triển thể lực, tới tình trạng thiếu vi chất dinh dưỡng, tới khả năng miễn dịch của trẻ, đã thu hút nhiêu nghiên cứu trong và ngoài nước.

Về cải thiện tình trạng thiếu máu: Nghiên cứu của chúng tôi có kêt quả khá tương đồng với nhiều nghiên cứu khác trên thế giới. Theo Haro và cộng sự, trẻ em tiêu thụ sữa bổ sung đa vi chất sẽ tăng hàm lượng hemoglobin lên $1,13 \mathrm{~g} / \mathrm{dL}$, hàm lượng ferritin huyết thanh tăng $5,83 \mu \mathrm{g} / \mathrm{L}$, hàm lượng kẽm huyết thanh tăng of $45.2 \mu \mathrm{g} / \mathrm{dL}(\mathrm{p}<0.05)$ [3]. Nghiên cứu của Sazawal và cộng sự cho thấy, so với trẻ ở nhóm chứng, trẻ ở nhóm được bổ sung sữa đa vi chất có nồng độ $\mathrm{Hb}$ tăng 13,6g/L (95\% CI: 11,1 $-16,0 ; p<0.001)$. Bổ sung sữa cũng làm giảm $88 \%$ tỷ lệ trẻ bị thiếu máu thiếu sắt $(95 \% \mathrm{CI}$ : $80 \%-92 \%, p<0,001)[4]$.

Có được sự cải thiện trong nghiên cứu của chúng tôi là do trẻ đã được bổ sung $360 \mathrm{ml}$ sữa/ ngày trong suốt 4 tháng. Ngoài việc được cung cấp thêm năng lượng, trẻ còn được bổ sung thêm một hỗn hợp khá đầy đủ các vitamin và khoáng chất trong đó có sắt, vitamin $C$ (giúp tăng cường hấp thu sắt). Do đó, nồng độ Hemoglobin trong máu và sắt huyết thanh được cải thiện. Ngoài ra, do tình trạng dinh dưỡng của trẻ được cải thiện nên cũng góp phần cải thiện tình trạng các vi chất này trong huyết thanh.

Thiếu sắt là một tình trạng khá phổ biến, không chỉ ở các nước đang phát triển mà cả ở cả các nước phát triển. Tai các nước đang phát triển, bổ sung sắt vào thực phẩm là một trong những giải pháp hiệu quả để cải thiện tình trạng này. Rất nhiều chương trình bổ sung đa vi chất đã chứng minh được hiệu quả trong việc cải thiện tình trạng thiếu vi chất dinh dưỡng tại các 
nước đang phát triển. Tuy nhiên, việc bổ sung sắt dưới dang viên uống đã được báo cáo lại rằng có thể sẽ gây ra các tác dụng không mong muốn tại các khu vực có tỷ lệ bị sốt rét cao [5]. Do vậy, việc sử dụng sữa có bổ sung thêm sắt và các vi chất dinh dưỡng khác có thể là một sự thay thế an toàn hơn để giải quyết tình trạng thiếu vi chất dinh dưỡng bởi sữa bổ sung đa vi chất dinh dưỡng sẽ làm giảm được nguy cơ quá liều và cho tới nay, vẫn chưa có một báo cáo nào ghi nhận các tác dụng không mong muốn của sữa bồ sung đa vi chất.

Về cải thiện nồng độ kẽm huyết thanh: Nghiên cứu của Nguyển Thanh Hà cho thấy bổ sung đa vi chất có tác dụng cải thiện nồng độ hemoglobin huyết thanh trong khi đó, bổ sung kẽm đơn thuần không hoặc rất ít cải thiện hemoglobin [6]. Lý do là vì bổ sung kẽm phẩn nào làm ức chế khả năng hấp thu sắt của cơ thể dẫn đến nồng độ hemoglobin không cải thiện. Sản phẩm sữa sử dụng cho nhóm can thiệp trong nghiên cứu của chúng tôi là một sản phấm được bổ sung phối hợp đồng thời cả sắt và kẽm, đồng thời được bổ sung thêm vitamin C, giúp tăng cường hấp thu sắt.

Mặc dù các kết quả còn chưa đồng nhất, nhưng có rất nhiều khuyến nghị từ các tổ chức lớn trên thế giới đồng ý rằng các nhóm dễ tổn thương, bao gồm cả nhóm trẻ mẫu giáo, nên được bổ sung đồng thời cả sắt và kẽm vào chế độ ăn. Nghiên cứu mới đây nhất của WHO/UNICEF về các loại thức ăn bổ sung ở các nước đang phát triển cũ̃ng đưa ra kết luận rằng rất khó để đáp ứng nhu cầu sắt và kẽm khuyến nghị nếu chỉ sử dụng các loại thực phẩm tự nhiên, không bổ sung vi chất [7].

Về cải thiện chỉ số IgA huyết thanh: do vấn đề phức tạp của hệ thống miễn dịch, nên đến nay chưa có một chỉ số nào có thể đại diện chính xác cho khả năng miễn dịch của cơ thể. Tuy nhiên, một trong những chỉ số được sử dụng nhiều nhất trong các nghiên cứu gần đây là khả năng sản xuất kháng thể IgA tại bề mặt của đường tiêu hoá, hoặc đường hô hấp một yếu tố rất quan trọng giúp vật chủ chống lại những tác nhân gây bệnh đường tiêu hoá [8]. IgA được coi là chỉ số khá phù hợp, được sử dụng cho các nghiên cứu can thiệp cộng đồng, do vậy chúng tôi đã tiến hành đanh giá mức IgA trong máu để đánh giá tình trạng miển dịch của trẻ.

IgA huyết thanh được sản xuất chủ yếu từ tế bào tuỷ xương, dưới dạng monomer IgA1, chiếm một số lượng lớn chỉ số miễn dịch trong máu, chỉ đứng sau IgG với số lượng bằng khoảng $1 / 5$ của IgG. Các yếu tố làm tăng IgA huyết thanh đã được xác định bao gồm nhiễm khuẩn mạn tính, bệnh tự miễn, bệnh gan mạn tính và một số bệnh khác. Tuy nồng độ IgA huyết thanh không phải là một chỉ số đáp ứng nhạy với tình trạng nhiễm khuẩn tại đường tiêu hoá, hô hấp bằng chỉ số IgA bài tiết tại ruột hoặc đường hô hấp, nhưng IgA huyết thanh lại đáp ứng rất tốt với tình trạng tiêm chủng phòng bệnh của trẻ. Bởi vậy, định lượng các IgA đặc hiệu phản ánh tình trạng đáp ứng miễn dịch của cơ thể trẻ chống lại các tác nhân gây bệnh này [8]. Tuy nhiên, IgA trong máu lại khá ổn định và không dao động quá lớn giữa các cá thể, bởi vậy giá trị trung bình IgA trong máu của quần thể lại có giá trị khi so sánh thống kê.

\section{KẾT LUÂ̂N}

Sử dụng sản phẩm sữa Care100Gold cao năng lượng, bổ sung đa vi chất dinh dưỡng có hiệu quả cải thiện rõ rệt tình trạng thiếu máu thiếu sắt và thiếu kẽm, cũng như có xu hướng gia tăng chỉ số miễn dịch, tốt hơn ý nghĩa so với sữa thông thường, ở trẻ em 36-60 tháng tuổi sau 4 tháng can thiệp.

\section{TÀI LIẸU THAM KHẢO}

1. IZiNCG, Assessing population zinc status with serum zinc concentration. 2012. 02.

2. WHO, Iron Deficiency Anaemia: Assessment, Prevention, and Control: A guide or programme managers. 2001.

3. Grijalva-Haro, M.I., et al., [Impact of fortified milk on the iron and zinc levels in Mexican preschool children]. Nutr Hosp, 2014. 29(2): p. 331-6.

4. Sazawal, S., et al., Micronutrient fortified milk improves iron status, anemia and growth among children 1-4 years: a double masked, randomized, controlled trial. PLoS One, 2010. 5(8): p. e12167.

5. Sazawal, S., et al., Effects of routine prophylactic supplementation with iron and folic acid on admission to hospital and mortality in preschool children in a high malaria transmission setting: community-based, randomised, placebo-controlled trial. Lancet, 2006. 367(9505): p. 133-43.

6. Nguyễn Thanh Hà, Hiệu quả bổ sung kẽm và sprinkles đa vi chất trên trẻ 6-36 tháng tuổi suy dinh dưỡng thấp còi tại huyện Gia Bình, tỉnh Bắc Ninh, in Viện Dinh dưỡng Quổc Gia. 2011.

7. WHO, Complementary feeding of young children in developing countries: a review of current scientific knowledge. . 1998: Geneva.

8. Suzuki $K$ and Nakajima A, New aspects of IgA synthesis in the gut. International Immunology, 2014. 26(9): p. 489-494. 